\title{
The supportive care needs of family members of men with advanced prostate cancer
}

by Nancy Carter, Denise Bryant-Lukosius, Alba DiCenso, Jennifer Blythe and Alan J. Neville

\section{Abstract}

This exploratory study identified the supportive care needs of family members of men with advanced hormone-sensitive (HS) and hormonerefractory (HR) prostate cancer. In focus groups and individual interviews, we asked eight family members of men with HS disease and 11 family members of men with HR disease to identify their supportive care needs and recommend strategies for improving care to meet these needs. Unmet needs common to both groups were lack of information and uncertainty about the future. Unmet needs specific to family members affected by HR prostate cancer related to caregiver burden, practical assistance, and isolation. Implications for practice to improve supportive care services for families affected by APC are provided.

Prostate cancer occurs most often in older men over the age of 65 years. In advanced or metastatic prostate cancer (APC), common problems related to urinary function, fatigue and pain are compounded by other age-related health issues and comorbidity (Harden, 2005). Two distinct populations of patients live with APC. Men with hormone-sensitive (HS) prostate cancer are treated with androgen deprivation therapy, which has a feminization effect, including erectile dysfunction. Eventually, most patients develop hormone "resistant," or hormone-refractory disease (HR), at which point the focus is on palliative treatment with chemotherapy, radiation, and supportive care (McMurtry \& McMurtry, 2003). As with any serious illness, prostate cancer affects the entire family, particularly spouses and partners (Maliski, Heilemann, \& McCorkle, 2002). The sexuality-related side effects of prostate cancer treatment affect intimate relationships and increase the stress of coping with a loved one's illness.

Previous studies identify that partners of men with prostate cancer often report higher levels of distress than the patients (Couper et al., 2006; Resendes \& McCorkle, 2006) and, as patient problems increase, partner quality of life decreases (Kornblith, Herr, Ofman, Scher, \& Holland, 1994). Problems reported by partners include distress related to worry and role strain (Harden, 2005), lack of information (Butler et al., 2000), difficulties with intimacy and sexuality (Couper et al., 2006; Crowe \& Costello, 2003; Sanders, Pedro, Bantum, \& Galbraith, 2006) and communication issues with their partners (Boehmer \& Clark, 2001b; Hawes et al., 2006; Lavery \& Clarke, 1999). Stage of illness is often not identified in studies of partners of men with prostate cancer (Crowe \& Costello, 2003; Feltwell \& Rees, 2004; Harden, Northouse, \& Mood, 2006; Manne, Babb, Pinover, Horwitz, \& Ebbert, 2004; Rees et al., 2003). Few studies have been designed to understand the needs of partners of men with APC and no studies distinguish between the partners of men with HS and HR disease.

As part of a larger program of research exploring the role of an advanced practice nurse in APC, this study used the participatory, evidence-based, patient-focused process for advanced practice nursing role development, implementation and evaluation (PEPPA) framework, as described by Bryant-Lukosius and DiCenso (2004). This nine-step framework emphasizes the importance of assessing patient and family needs and identifying priority problems and goals to fully inform what additional health services are needed and who should deliver them.

In this paper, we focus on the needs of family members of men with APC. Specifically, we addressed the following research questions: 1) what are the supportive care needs of the family members of men with advanced HS and HR prostate cancer and how do they differ? and, 2) what are the recommended strategies for improving care to meet the supportive needs of family members?

\section{Methods}

This study was a needs assessment using a qualitative descriptive method outlined by Sandelowski (2000). We collected information from the family members of men with HS and HR prostate cancer separately because of reported differences in the health care needs of men with different forms of APC (Bryant-Lukosius et al., 2010). Eligible family members included wives, partners and children of patients with APC. We recruited participants from various settings including urologists' offices, a regional cancer centre and local prostate support groups. We identified many participants through a companion study of patients with APC (Carter, Bryant-Lukosius, DiCenso, Blythe \& Neville, in press).

\section{Data collection and analysis}

We collected data through in-depth interviews and focus groups. Participants completed a consent form and a short demographic questionnaire prior to data collection. Interviewees took part in one 40- to 90-minute semi-structured interview and focus group participants in one 60- to 90-minute focus group. The principal investigator (NC) conducted all interviews and focus groups. We asked participants how APC affected their lives, the problems they experienced, and if their needs were met. We also asked them to prioritize future efforts to improve care. We used the same semistructured interview guide for interviews and focus groups (see Appendix A). At the end of the interviews and focus groups, the investigator summarized the priority needs and suggested strategies and recapped the major themes to validate and clarify the information (member checking). All focus groups, interviews and reflections were audiotaped and transcribed.

We analyzed data concurrently with data collection. The research team independently read initial transcripts and developed a coding scheme. The primary investigator and two research assistants with

\section{About the authors}

Nancy Carter, RN, PhD, School of Nursing, Faculty of Health Sciences, McMaster University, 1200 Main Street West, HSC-3N25A, Hamilton, ON L8N 3Z5. Phone: (905) 525-9140 x22221; Email: carternm@mcmaster.ca

Denise Bryant-Lukosius, RN, PhD, Assistant Professor, School of Nursing \& Department of Oncology, Faculty of Health Sciences, McMaster University; Jointly Appointed to the Juravinski Cancer Centre, Hamilton, ON.

Alba DiCenso, RN, PhD, Professor, School of Nursing \& Department of Clinical Epidemiology and Biostatistics, Faculty of Health Sciences, McMaster University, Hamilton, ON.

Jennifer Blythe, PhD, Associate Professor, School of Nursing, Faculty of Health Sciences, McMaster University, Hamilton, ON.

Alan J. Neville, MBChB, MEd, MRCP, FRCP(c), Professor, Medicine, and Assistant Dean, Undergraduate MD Program, Faculty of Health Sciences, McMaster University, Hamilton, ON. 
oncology nursing experience reviewed all transcripts and used the coding scheme and N-Vivo software to develop core categories. We clustered codes into categories and significant themes emerged. The researcher and research assistants discussed data saturation and agreed when no new themes were identified and when data collection could stop. The University Research Ethics Board and the Hospital Healthcare Research Ethics Board provided approval to conduct this study.

\section{Results}

\section{Participant characteristics}

We collected data from 19 family members; 11 of men with HR disease and eight of men with HS disease (Table 1). Ten of the $11 \mathrm{HR}$ family members participated in one of three focus groups. Of these 10 focus group participants, nine were wives and one was a daughter who attended with her mother. We interviewed one HR family member at home with her husband. The ages of wives of men with HR disease ranged from 53 to 85 years. The daughter who attended with her mother was 56 years old. We also interviewed eight family members of men with HS disease (six wives, one son, and one daughter). The ages of the six wives ranged from 63 to 85 years. The interviewed son was 52 years old and his mother was not a study participant. The daughter who participated in the study was 32 years old and her stepmother was a study participant.

\section{Supportive care needs of family members}

Analysis of data revealed five major themes related to supportive care needs. Although both family members of men with HS and with HR prostate cancer had similar issues and experiences in living with prostate cancer, there were some notable differences relating to the level of wellness and advanced burden of illness with HR disease. Both groups of family members expressed a need for information and uncertainty about the future. Different treatment regimens, particularly chemotherapy, resulted in more supportive care needs for the family members of men with HR. Data from this group revealed issues relating to caregiver burden, the need for practical assistance and isolation. We describe these themes in more detail below.

\section{Similar needs of family members of men with HS and HR prostate cancer Informational needs}

Family members of men with advanced HS and HR prostate cancer wanted more information about treatments and side effects, available supportive care services, and the future course of the disease. One HR family participant said: "From where I'm sitting, it's just a lack of information. A lack of what's available out there. So unless you specifically ask, you don't find out. Sometimes you just don't know what question to ask because you don't know what's out there." Study participants felt they were not given enough

Table 1. Description of family participants

\begin{tabular}{|l|l|l|}
\hline & $\begin{array}{l}\text { Hormone } \\
\text { refractory } n=11\end{array}$ & $\begin{array}{l}\text { Hormone } \\
\text { sensitive } n=8\end{array}$ \\
\hline Number of wives & 10 & 6 \\
\hline Mean age of wives (range) & $\begin{array}{l}71 \text { years } \\
(53-85 \text { yrs })\end{array}$ & $\begin{array}{l}69 \text { years } \\
(63-85 \text { yrs })\end{array}$ \\
\hline Number of adult children & 1 & 2 \\
\hline Ages of adult children & 56 yrs & 32 yrs, 52 yrs \\
\hline $\begin{array}{l}\text { Data collection: } \\
\text { Focus group } \\
\text { Interview }\end{array}$ & 10 & 0 \\
\hline
\end{tabular}

information, and felt responsible for asking the appropriate questions to find out what they needed to know. The focus group participants engaged in frequent information sharing. Most wives reported that physicians were their main sources of information, but the information they received at medical appointments was either overwhelming or difficult to understand. Several older family members stated that their hearing loss exacerbated the frustration they experienced at the doctor's office. They also described feeling rushed during physician appointments. Women seemed reluctant to ask questions at medical appointments, unsure if doing so was their prerogative. One HS family participant said: "I have different questions than he does and I don't want to upset him, you know." By refraining from asking questions to avoid upsetting her husband, her information needs were not met.

Younger family members accessed the internet for information, but many of the older participants did not use this resource. One risk of searching the internet was receiving too much information. One woman said: "Knowledge is very powerful, but don't mistake it, because sometimes just that little bit, if you don't know how to put the pieces together, can be very terrifying. We've stopped looking at the internet because of that."

\section{Uncertainty about the future}

Both HS and HR family members discussed their feelings of uncertainty about the future and their frustration with not knowing what to expect as the prostate cancer progressed. One HS family participant said: "Basically he's just as he was before, except with a little PSA signpost hanging over his head. Like, okay, when's the count going to change?" The threat of her husband's tenuous condition was constant, despite the fact that he seemed the same as he was before prostate cancer. Frequently, family members wondered how the future progression of the cancer would affect their loved one. This HR participant felt providers withheld information: "What the future holds? Nobody has a crystal ball or no one actually tells you. Hopefully we can go on for a couple of years like this. I just don't know. But I don't want to see him live and suffer." She could cope with her husband's current condition, but was afraid he would suffer in the future. Family members were unsure if they could manage their loved ones' worsening condition. One HS participant said: "I don't know if he suddenly became ill. He said one day, "Don't ever try to keep me home," and I said, "Well I know I couldn't cope. I just couldn't."

\section{Unique needs of family members of men with HR prostate cancer}

In addition to the needs identified above, family members of men with advanced HR prostate cancer experienced additional problems and needs, likely due to progression of disease and its related symptoms.

\section{Caregiver burden}

Most family members were reluctant to discuss their own needs and downplayed the personal effects of living with a man with APC. Several HR family members described the burden of supporting the men's physical, functional, and emotional needs. One family member of a patient with HR disease said: "It is a constant battle trying to give them the positive end." She worked to present an emotionally positive façade, which was difficult for her. One HR spouse described the burden of providing emotional support to her husband while not disclosing to family and friends how sick he was. She said: "But he's had this cancer since 1997 and you would never know it because he would tell everybody he's fantastic. His favourite saying if he is asked, "How are you?" "Oh, I'm fantastic!" I'm the only one that really knows." She was unable to obtain support for herself without betraying her husband's wish to keep the prostate cancer a secret. 


\section{Need for practical assistance}

Wives of men with advanced HR prostate cancer needed practical assistance. They described their inability to keep up with household chores. They now had to do jobs previously done by their husbands, such as yard work and snow removal. They described efforts to organize care for their husbands, including mundane tasks like keeping medications straight. Very few of them described the toll this extra work took on their health and some women described being tired. This HR participant described her concerns in this way: "I don't want to feel that I'm indispensable, but I just wonder sometimes what he would do if I wasn't there, you know? And I do worry about my own health."

\section{Isolation}

For some HR family members, the burden of caregiving led to feelings of isolation. They reported that the men did not want to go outside the home because of incontinence and fatigue. An adult daughter concerned about her mother's isolation said: "Mom needs more activities. She needs to get out and socialize more, but she doesn't want to leave him. I think he enjoys seeing family, but he wants to stay at home. That's not necessarily where Mom wants to be or needs to be and so we've got these needs that are just totally opposite right now." Another man's constant fatigue prevented his family member from having visitors to her home. Participants needed to get out and socialize, but were reluctant to do so. One woman said: "It affects your social life, as well. It just doesn't feel good to be out enjoying yourself and he's at home suffering. Occasionally, I know I need to go out. But I know he'd do the same for me if the table was turned."

\section{Strategies for improving delivery of supportive care service}

Most family members were satisfied with the care their family member with APC was receiving. Their suggestions for improvement included augmenting access to information. They wanted increased access to informed health care providers. Family members wanted more time with knowledgeable people who understood their husband's condition. They recommended the development of family resource centres. Both HS and HR family members suggested family support groups, as well. Many women emphasized the need for support specific to their loved one's stage of cancer. Only one woman requested support for herself at home.

\section{Discussion}

To the best of our knowledge, this is the first needs assessment that identifies and compares the needs of family members of men with advanced HS and HR prostate cancer and elicits their suggestions for improvements in care delivery. Both groups of family members identified the need for additional information, as their priority supportive care need. When Resendes and McCorkle (2006) examined the literature on the responses of wives of men diagnosed with prostate cancer who had undergone prostatectomy, they identified lack of information to be a source of distress. In an earlier study, men with prostate cancer $59 \%$ of whom had advanced disease) and their partners who participated in focus groups also reported an overwhelming need for information (Harden et al., 2002).

Family members expressed the need for more information about treatments and side effects, available supportive care services, and the future course of the cancer. This need is consistent with that found in other studies (Butler, Downe-Wamboldt, Marsh, Bell, \& Jarvi, 2000; Davison et al., 2002; Finney Ruttin, Squiers, \& Treiman, 2006; Giarelli et al., 2003). Most family members reported reliance on health care professionals as their primary source of information. This finding is somewhat inconsistent with the results of a study of Canadian men and their partners by Davison et al. (2002) in which the partners reported that their main sources of information (from most to least accessed) were friends or relatives, other men with prostate cancer, reading material in doctors' offices, physicians, and the internet. Few family members in the current study accessed the internet. The large amount of detailed information on the internet was confusing and made family members anxious.

Prior research identifies a conflict between seeking and avoiding information. In their study of the information-seeking behaviours of partners of men with prostate cancer, Feltwell and Rees (2004) found information needs were individualistic, with some seeking large amounts of information and others wishing to avoid receiving information. Wong et al. (2002) found the use of the internet was the least-favoured method of obtaining information in their survey of Canadian patients with advanced cancer and their caregivers. Both Wong and Davison's studies were published in 2002 and views of the internet may have changed over time, as people have become more accustomed to its use.

In the current study, hearing problems, difficulty processing medical information, and insufficient access to and time with physicians were challenges compounding family members' ability to receive information from health care professionals. Fitch (2006) identified many problems for older adults receiving cancer information, including the hectic nature of the health care environment, the rapid rate of speaking, the use of medical terminology, and the overwhelming volume of information.

Participants in both the HS and HR groups reported feeling uncertain about what the future would hold for them and their loved ones. They needed more information about the next treatment/health care step and its consequences. Consistent with this, Shaha and colleagues' (2008) exploration of the literature to discover key aspects of uncertainty expressed by patients with breast, prostate and colorectal cancer revealed three sources of uncertainty: 1) information-related issues after diagnosis; 2) decisions about treatment; and, 3) the effect of cancer on the lives of patients and families over the disease trajectory. This is particularly challenging in prostate cancer because of the various treatment options about which couples must make decisions. Another study also suggested patients with terminal cancer and their families want general information about the life experience of other patients, but not specifics of their own situation (Clayton, Butow, Arnold, \& Tattersall, 2005).

In their review of the psychosocial responses of spouses of men who had undergone prostatectomy, Resendes and McCorkle (2006) found fear of the unknown and the future distressing. Our study findings confirm these results. In their qualitative study using focus groups to explore the experiences of couples living with prostate cancer, Harden and colleagues (2002) found an emerging theme of enduring uncertainty. This included struggling with choices and feeling as if one was on an emotional roller coaster. Kershaw and colleagues (2008) report spouses found communication with their husbands helped to reduce uncertainty.

HR family members, but not HS family members, experienced isolation. Various aspects of prostate cancer contribute to this isolation, particularly changes in participants' social activity due to physical problems such as incontinence and fatigue. Harden (2005) explored disease-specific issues in couples experiencing prostate cancer and found that changes in normal patterns of socialization led to loneliness for caregivers. Spouses reported significantly less social support compared to patients in a study by Northouse and colleagues (2007). Butow and colleagues (2007) report that feelings of isolation are one of the most important reasons patients and carers join support groups. In our study, several women did not participate in their usual activities because they did not want to leave their spouses alone. One daughter poignantly described the opposing needs of her father and mother, with her mother needing some social release from caregiver activities.

Boehmer and Clark (2001b) described how couples often isolate themselves from each other by avoiding both communication and working through their feelings together. They also reported that 
men's communication about their cancer is often restricted to their wives only. This was poignantly confirmed in our study. One study participant said: "I am the only one who really knows." In their quality of life study of men and their spouses, Kornblith et al. (1994) found that urinary problems were associated more strongly to the spouse's distress than to the patient's distress. They suggest that distress arises from the limitations that urinary problems put on the couple's social life and/or fears of social embarrassment related to incontinence.

Harden (2005) noted that caregivers have multiple role responsibilities at home and because of their spouses' fatigue and ill health. For older spouses, these additional responsibilities add to their own health issues and increase their own need for support (Hawes et al., 2006). The family members in the current study found it difficult to discuss their own needs, particularly those related to the burden of caregiving.

Sinfeld et al. (2009) report couples wanted more information to help them look after themselves at home. In our study, family members reported having to go out of their way to obtain information about available services or to arrange for supportive care. Previous research found that caregiving families are consistently unaware of available support services despite the presentation of such information by health care professionals (Hardwick \& Lawson, 1995). Galbraith et al. (2008) recommend that nurses not only actively include partners when delivering information, but also involve them in care processes and seek their input to ensure they are informed.

The lack of coordination and wide geographical spread of available services are limitations of the health care system. Several participants recommended developing family resource centres as a means of consolidating available services and increasing access to health care professionals. In their survey of 71 Canadian patients with advanced cancer and 73 caregivers, Wong et al. (2002) found that most participants preferred receiving information in a "one-on-one" situation with a health professional. Participants in our study also suggested the formation of small support groups in which they could both receive information and interact with other family members, a suggestion previously made by Harden and colleagues (2002).

A limitation of this study is the inconsistency in data collection methods. The majority of HR family members participated in focus groups while HS family members participated in individual face-toface interviews. The decision to use both methods allowed us to gather information from individuals who might not have participated otherwise. For example, some family members did not want to leave their husbands alone to attend a focus group. Another limitation of the study is that we report on data from participants, but do not understand the needs of non-participants in the study. The non-participant group of family members could include those who are well and do not use supportive care services. But, more importantly, there is likely a group of family members who are vulnerable and may suffer from their own health problems and lack of social support. We need to discover new ways of engaging the neediest and most vulnerable family members of patients with cancer to ensure their needs are also addressed. Because we recruited from various locations (a regional cancer centre, local urologist offices, and through community advertising), a strength of the study is the opportunity to learn about the experiences of a spectrum of family members living with APC patients.

\section{Conclusions}

Family members of men with APC play a vital role in their care and we must create health care services to support them in their caregiving roles. The need is urgent for the elderly spouses of men with HR prostate cancer. The demands of caregiving and feelings of isolation overburden this group. Women may require additional home support to manage the increased household responsibilities they assume due to their husband's declining level of physical function. Men's needs to maintain their functional capacity and "normalcy" may be a source of conflict for family members who are concerned with caring for their loved ones. In this study, family members expressed frustration resulting from men's stoicism in the face of fatigue and pain. Family members also needed emotional support to help them cope with their own fear, uncertainty and feelings associated with the illness of their partners. Future research should focus on the impact of unmet emotional needs and distress of family members on the health of men with APC. Kim and colleagues (2008) found evidence that women's distress predicted men's physical health regardless of men's distress, survivor age or cancer stage.

Progressive disease limits the ability of family members to leave the home and their ill loved ones. Home support services, such as "respite support" or homemaking services may lessen the burden experienced by "housebound" caregivers, but our study identified a number of issues that limited access to these services. Participants lacked information about existing services and others were reluctant to ask for help. Further research is required to understand the reluctance of some family members and patients to ask for assistance if we are to understand the fit between what is currently available and what is utilized.

The family members of cancer patients require information to help them care for their loved ones, as well as cope personally (Finney Ruttin, Squiers, \& Treiman, 2006). We recommend the development and evaluation of small stage-specific peer support groups for family members of men with HS and HR prostate cancer led by health care professionals. Focused support group interventions were effective in helping spouses cope when their partners experienced an acute cardiac event (Gerwick, 1999) or spinal cord injury (Sheija \& Manigandan, 2005). Our study participants wanted more time and interaction with health care professionals who understand APC. Involving families in the assessment of current services and seeking their input in the redesign of supportive care services was the focus of this research. By exploring family needs and eliciting suggestions for care delivery, we were able to identify the priorities of this study population. Family involvement in the development and evaluation of new services is essential to ensure utilization.

\section{Appendix A. Interview Guide}

1. How has your life and that of your family member been affected by his diagnosis of advanced prostate cancer?

2. What needs, problems, or concerns have you and your family member experienced since his diagnosis of advanced prostate cancer?

3. How well have these needs, problems and concerns been met or resolved?

4. What are the helpful and unhelpful strategies you and your family member have used to cope with these needs, problems, or concerns?

5. How has the health care system, such as your doctors, nurses, the cancer centre and other health care services or community agencies been helpful/unhelpful in meeting these needs, problems, or concerns?

6. Based on your experiences, how could the delivery of health care services be improved to better meet these needs?

7. What needs would you identify as priorities for the focus of future efforts to improve the care of patients and families affected by advanced prostate cancer? 


\section{References}

Boehmer, U., \& Clark, J.A. (2001b). Communication about prostate cancer between men and their wives. Journal of Family Practice, 50, 226-231.

Bryant-Lukosius, D., Browne, G., DiCenso, A., Whelan, T., Gafni, A., Neville, A., \& Sathya, J. (2010). Evaluating health-related quality of life and priority health problems in patients with prostate cancer: A strategy for defining the role of the advanced practice nurse. Canadian Oncology Nursing Journal, 20(1), 5-14. French version on CANO website: http://www.cano-acio.ca/

Bryant-Lukosius, D., \& DiCenso, A. (2004). A framework for the introduction and evaluation of advanced practice nursing roles. Journal of Advanced Nursing, 48, 530-540.

Butler, L., Downe-Wamboldt, B., Marsh, S., Bell, D., \& Jarvi, K. (2000). Behind the scenes: Partners' perceptions of quality of life post radical prostatectomy. Urologic Nursing, 20, 254-258.

Butow, P.N., Kirsten, L.T., Ussher, J.M., Wain, G.V., Sandoval, M., Hobbs, K.M., et al. (2007). What is the ideal support group? Views of Australian people with cancer and their carers. PsychoOncology, 16, 1039-1045.

Carter, N., Bryant-Lukosius, D., DiCenso, A., Blythe, J., \& Neville, A. (in press). The supportive care needs of men with advanced prostate cancer. Oncology Nursing Forum.

Clayton, J.M., Butow, P.N., Arnold, R.M., \& Tattersall, M.H. (2005). Discussing life expectancy with terminally ill cancer patients and their carers: A qualitative study. Supportive Care in Cancer, 13, 733-742.

Couper, J., Bloch, S., Love, A., Macvean, M., Duchesne, G. M., \& Kissane, D. (2006). Psychosocial adjustment of female partners of men with prostate cancer: A review of the literature. PsychoOncology, 15, 937-953.

Crowe, H., \& Costello, A.J. (2003). Prostate cancer: Perspectives on quality of life and impact of treatment on patients and their partners. Urologic Nursing, 23, 279-282.

Davison, B.J., Gleave, M.E., Goldenberg, S.L., Degner, L.F., Hoffart, D., \& Berkowitz, J. (2002). Assessing information and decision preferences of men with prostate cancer and their partners. Cancer Nursing, 25, 42-49.

Feltwell, A.K., \& Rees, C.E. (2004). The information-seeking behaviours of partners of men with prostate cancer: A qualitative pilot study. Patient Education \& Counseling, 54, 179-185.

Finney Ruttin, L.J., Squiers, L., \& Treiman, K. (2006). Requests for information by family and friends of cancer patients calling the national cancer institute's cancer information service. PsychoOncology, 15, 664-672.

Fitch, M. (2006). Perspectives of older adults about the cancer information they receive. European Journal of Oncology Nursing, 10, 216-217.

Galbraith, M.E., Pedro, L.W., Jaffe, A.R., \& Allen, T.L. (2008). Describing health-related outcomes for couples experiencing prostate cancer: Differences and similarities. Oncology Nursing Forum, 35, 794-801.

Gerwick, M.A. (1999). Impact of a focus support group on spouse's coping and support of their mate's recovery from an acute cardiac event (Unpublished Doctor of Philosophy thesis) University of Pittsburgh, Pittsburgh, PA.

Giarelli, E., McCorkle, R., \& Monturo, C. (2003). Caring for a spouse after prostate surgery: The preparedness needs of wives. Journal of Family Nursing, 9, 453-485.

Harden, J. (2005). Developmental life stage and couples' experiences with prostate cancer: A review of the literature. Cancer Nursing, 28, 85-98.

Harden, J., Schafenacker, A., Northouse, L., Mood, D., Smith, D., Pienta, K., et al. (2002). Couples' experiences with prostate cancer: Focus group research. Oncology Nursing Forum, 29, 701-709.
Harden, J.L., Northouse, L.L., \& Mood, D.W. (2006). Qualitative analysis of couples' experience with prostate cancer by age cohort. Cancer Nursing, 29, 367-377.

Hardwick, C., \& Lawson, N. (1995). The information and learning needs of the caregiving family of the adult patient with cancer. European Journal of Cancer Care, 4, 118-121.

Hawes, S.M., Malcarne, V.L., Ko, C.M., Sadler, G.R., Banthia, R., Sherman, S.A., et al. (2006). Identifying problems faced by spouses and partners of patients with prostate cancer. Oncology Nursing Forum, 33, 807-814.

Kershaw, T.S., Mood, D.W., Newth, G., Ronis, D.L., Sanda, M.G., Vaishampayan, U., et al. (2008). Longitudinal analysis of a model to predict quality of life in prostate cancer patients and their spouses. Annals of Behavioural Medicine, 36, 117-128.

Kim, Y., Kashy, D.A., Wellisch, D.K., Spillers, R.L., Kaw, C.K., \& Smith, T.G. (2008). Quality of life of couples dealing with cancer: Dyadic and individual adjustment among breast and prostate cancer survivors and their spousal caregivers. Annals of Behavioural Medicine, 35, 230-238.

Kornblith, A.B., Herr, H.W., Ofman, U.S., Scher, H.I., \& Holland, J.H. (1994). Quality of life of patients with prostate cancer and their spouses. Cancer, 73, 2791-2802.

Lavery, J.F., \& Clarke, V.A. (1999). Prostate cancer: Patients' and spouses coping and marital adjustment. Psychology, Health \& Medicine, 4, 289-302.

Maliski, S.L., Heilemann, M.V., \& McCorkle, R. (2002). From "death sentence" to "good cancer": Couples' transformation of a prostate cancer diagnosis. Nursing Research, 51, 391-397.

Manne, S., Babb, J., Pinover, W., Horwitz, E., \& Ebbert, J. (2004). Psychoeducational group intervention for wives of men with prostate cancer. Psycho-Oncology, 13, 37-46.

McMurtry, C.T., \& McMurtry, J.M. (2003). Metastatic prostate cancer: Complications and treatment. Journal of the American Geriatrics Society, 51, 1136-1142.

Northouse, L.L., Mood, D.W., Montie, J.E., Sandler, H.M., Forman, J.D., Hussain, M., et al. (2007). Living with prostate cancer: Patients' and spouses' psychosocial status and quality of life. Journal of Clinical Oncology, 25, 4171-4177.

Rees, C.E., Sheard, C.E., \& Echlin, K. (2003). The relationship between the information-seeking behaviours and information needs of partners of men with prostate cancer: A pilot study. Patient Education \& Counseling, 49, 257-261.

Resendes, L.A., \& McCorkle, R. (2006). Spousal responses to prostate cancer: An integrative review. Cancer Investigation, 24, 192-198.

Sandelowski, M. (2000). Whatever happened to qualitative description? Research in Nursing \& Health, 23, 334-340.

Sanders, S., Pedro, L.W., Bantum, E.O., \& Galbraith, M.E. (2006). Couples surviving prostate cancer: Long-term intimacy needs and concerns following treatment. Clinical Journal of Oncology Nursing, 10, 503-508.

Shaha, M., Cox, C.L., Talman, K., \& Kelly, D. (2008). Uncertainty in breast, prostate and colorectal cancer: Implications for supportive care. Journal of Nursing Scholarship, 40, 60-67.

Sheija, A., \& Manigandan, C. (2005). Efficacy of support groups for spouses of patients with spinal cord injury and its impact on their quality of life. International Journal of Rehabilitation Research, 28, 379-383.

Sinfeld, P., Baker, R., Camosso-Sefinovic, J., Colman, A.M., Tarrant, C., Mellon, J.K., et al. (2009). Men's and carers' experiences of care for prostate cancer: A narrative review. Health Expectations, 12, 303-312.

Wong, R.K., Franssen, E., Szumacher, E., Connolly, R., Evans, M., Page, B., et al. (2002). What do patients living with advanced cancer and their carers want to know? A needs assessment. Supportive Care in Cancer, 10, 408-415. 